\title{
The role of E-cadherin and $\beta$-catenin in laryngeal cancer
}

\author{
Carlos Eduardo Nardi ${ }^{1}$, Rogério Aparecido Dedivitis ${ }^{1}$, Ricardo Camillo de Almeida ${ }^{2}$ \\ Leandro Luongo de Matos $^{3}$ and Claudio Roberto Cernea ${ }^{4}$ \\ ${ }^{1}$ Department of Head and Neck Surgery, Hospital das Clínicas, São Paulo School of Medicine, São Paulo, Brazil \\ ${ }^{2}$ Pathologist, Clínica Diagnos, Santos, Brazil \\ ${ }^{3}$ Department of Head and Neck Surgery, São Paulo School of Medicine, Assistant, Instituto do Câncer do Estado de São \\ Paulo, ICESP (São Paulo State Cancer Institute), São Paulo, Brazil \\ ${ }^{4}$ Department of Head and Neck Surgery, São Paulo School of Medicine, University of São Paulo, São Paulo, Brazil \\ Correspondence to: Carlos Edvardo Nardi, email: nardi.cem@gmail.com \\ Keywords: cadherins; beta-catenin; laryngectomy; laryngeal neoplasms; carcinoma
}

Received: October 18, $2017 \quad$ Accepted: June 04, $2018 \quad$ Published: July 10, 2018

Copyright: Nardi et al. This is an open-access article distributed under the terms of the Creative Commons Attribution License 3.0 (CC BY 3.0), which permits unrestricted use, distribution, and reproduction in any medium, provided the original author and source are credited.

\section{ABSTRACT}

Epithelial cadherins with catenins form the E-cadherin-catenin complex that acts on cell-to-cell adhesion. The loss of these complex lead to the reduction or absence of epithelial cadherin expression in the cell membrane, cytoplasmic accumulation of $\beta$-catenin and its translocation to the nucleus, contributing to carcinogenic events. The objective of this study was to evaluate the expression of epithelial cadherin and $\beta$-catenin in patients with laryngeal tumor. A retrospective study of 52 patients with glottic or supraglottic squamous cell carcinoma was conducted and evaluated according to the tumor site, histological differentiation, TNM stage, survival analysis and compared with the immunohistochemical expression of epithelial cadherin and $\beta$-catenin. We observed statistically significant association between the epithelial cadherin expression reduction and supraglottic localization of the lesion, the presence of cervical metastasis, poorly differentiated tumors and locally advanced tumors when in glottic topography. Related to the expression of $\beta$-catenin, statistical significance was also found to the presence of cervical metastasis and tumor of low differentiation with the decreased expression of this marker. Regarding survival analysis, the low expression of $\beta$-catenin is related to worse overall survival and the reduction of expression of both markers to worse disease-free survival. We concluded that the reduction in expression of the markers studied leads to a prognostic impact as they are related to tumors with greater local aggressiveness and presence of cervical metastasis.

\section{INTRODUCTION}

Larynx cancer is the second most common malign neoplasm in the cervicofacial segment. It occurs in males in the proportion of 3.5:1 in relation to females [1]. Larynx neoplasms present greater incidence from the sixth and seventh decades of life $[1,3]$. The presence of lymph node metastasis determines the treatment and prognosis for larynx squamous cell carcinoma (SCC) patients, reducing expected survival by up to $50 \%[4,5]$.

Cadherins are a group of cellular adhesion molecules $[6,7]$. Epithelial cadherins (E-cadherins) are expressed in all human epithelial tissues and are concentrated in sites of cell-cell epithelial contact [8], whereas catenins of $\beta$ and 
$\gamma$ type make a direct link with the the cytoplasmic portion of E-cadherin, forming the E-cadherin-catenin complex.

The decrease in expression of the E-cadherin molecule leads to the loss of cellular adherence, cytoplasmatic accumulation of $\beta$-catenin and its translocation to the nucleus, stimulating cellular proliferation and invasion of epithelial cells [9], increasing the risk towards adjacent or lymph node dissemination [10-12].

The E-cadherin human gene is located in the chromosome 16q22 [13], a region subject to chromosomal translocation in head and neck squamous cell carcinomas [14].

The immunohistochemical expression of E-cadherin and $\beta$-catenin in the primary tumor seems to be useful in the identification of patients with clinically negative neck that are considered at risk for hidden metastasis and would need additional treatment.

Some studies have failed to demonstrate a significant statistic relationship between the reduction of the expression of E-cadherin and tumor clinicalhistological characteristics, therefore, new investigations are necessary to confirm if the E-cadherin/caterin complex would be important in the clinical decision.

This study aims to assess the influence of the expression of E-cadherin and $\beta$-catenin in patients with early or advanced laryngeal tumor and with the presence or absence of cervical metastasis.

\section{MATERIALS AND METHODS}

The casuistry was made by the analysis of consecutive patients with laryngeal cancer in a retrospective cohort between 1996 and 2011.

Inclusion criteria were: patients with glottic or supraglottic squamous cell carcinoma; treated at the Service of Head and Neck Surgery of Hospital Ana Costa de Santos and the Service of Head and Neck Surgery of Irmandade Santa Casa da Misericórdia de Santos; submitted to partial or total laryngectomy with or without neck dissection; therapeutic procedures performed by the same team of surgeons following the same techniques and with curative intent.

Exclusion criteria were: patients whose treatment was radiotherapy, associated or not with chemotherapy; patients submitted to previous surgery and/or oncologic procedures in the superior aerodigestive tract; patients with low histological representativeness in their slides and blocks.

Patients were staged according to the TNM system, eighth edition of the Union for International Cancer Control (UICC, 2017) [15], and assessed according to their age (measured in years), gender (male or female), tumor site (glottic or supraglottic), T stage (T1 to T4), N stage $(\mathrm{N} 0$ and $\mathrm{N}+$ ) and degree of histological differentiation (well differentiated, moderately differentiated or poorly differentiated). Data such as disease-free survival and global survival were also assessed and quantified in months. The data cited were compared with the immunohistochemical expression of the markers E-cadherin and $\beta$-catenin.

Slides were obtained by using paraffin blocks of patients treated for the diseases mentioned and stained with hematoxylin and eosin, aiming at proving tumor representation in the material to be analyzed. A tissue microarray (Beecher Instruments, Silver Spring, MD) paraffin receptor block was built from original samples (donor block), the area of lesion representation was chosen and marked with a circle, followed by collection with a $1.0 \mathrm{~mm}$ diameter needle (TMArrayer punch MP10-1.0 mm). A $3 \mu \mathrm{m}$ thick serial cuts were fixed on to glass slides. Sample staining was performed with hematoxylin and eosin.

Immunohistochemical analysis comprised the evaluation of the expression of polyclonal E-cadherin (clone 36, Ventana Medical Systems Inc. ${ }^{\circledR}$ ) and $\beta$-catenin (Clone 14, Cell Marque $^{\circledR}$ ). This analysis was performed by using the samples obtained from tissue microarray receptor blocks, which were deparaffinized and prepared by successive immmersion in xylol and ethanol, and submitted to antigen retrieval by heat provided by a pressure cooker, using citrate buffer $10 \mathrm{mM}$ pH6.0. The slides were covered by a saline solution at $4 \%$ (3-aminopropyl-triethoxi-silane, Sigma ${ }^{\circledR}$, Saint Louis, USA) diluted in acetone, using the streptovidin-biotin complex (StreptoABC, Dako ${ }^{\circledR}$ ) to obtain reactions.

With the samples obtained, the endogenous peroxidase was blocked with a solution of hydrogen peroxide at $3 \%$ in methanol, immediately after cooling at room temperature for 20 minutes; the slides were rinsed in distilled water. After the peroxidase blocking, immersion took place in Phosphate Buffered Saline solution (PBS).

The slides were incubated with primary antibodies. Subsequently, they were incubated with secondary antibody at titration of 1:200. The use of Diaminobenzidine (DAB, Sigma $^{\circledR}$ ) solution, sensitive to light and counter stained with Harris $\left(\right.$ Merck $\left.^{\circledR}\right)$ hematoxylin, showed the reactions. These reactions were accompanied by identification of positive controls, in the absence of primary antibodies, and negative ones when there were no secondary antibodies.

The immunoexpression of every marker was calculated by the counting of one thousand cells, including tumor tissue and non-neoplastic tissue, in every core of the confectioned TMA block and then calculated the percentage of expression to each marker.

Distribution of frequencies was used to describe the category variables (number of cases and percentages) and the measures for central tendency (mean and median) and numeric variables (minimum, maximum and standard deviation). The association between the category variables and the expression measures for E-cadherin and $\beta$-catenin was checked through the non-parametric 
$U$ Mann-Whitney test and the Kruskal-Wallis test when the category variable presented 3 categories. The ShapiroWilk test was applied to verify the normality of data. Global survival probability and recurrence free survival probability were estimated by the Kaplan-Meier curve, and the log-rank test was applied to check differences between the survival curves from each variable. A 5\% level of significance was adopted for all the statistical tests and the STATA program for computers version 10.0 was used for the performance of the statistical analyses.

\section{RESULTS}

Three patients were excluded for not presenting histological representation after the staining with hematoxylin and eosin, and 4 others were also excluded after material loss during the TMA production.

Table 1 describes selected patient clinical data and their clinic pathological characteristics as well the separation of study groups by site and local progression, with 15 cases in each group. The average age was 63 years with $73.3 \%$ of the male gender, $66 \%$ of glottic site, $62.2 \%$ locally advanced and $44.4 \%$ with the presence of lymph node metastasis.

The distribution of cases according to the markers analyzed is described in Table 2 . The average frequency expression for E-cadherin was $62.1 \%$ and $44.3 \%$ for $\beta$-catenin.

Table 3 shows the associations between the measures of the studied variables according to E-cadherin expression. We observed statistical significance in the case of a reduction in E-cadherin expression in advanced glottic tumors, when compared to early ones, in the occurrence of cervical metastasis and in poorly differentiated tumors (Figure 1).

Table 4 represents the $\beta$-catenin correlation with the selected studied cases. It was observed that low levels of $\beta$-catenin are associated with the occurrence of worse tumor differentiation and cervical dissemination (Figure 2).

Data such as global survival in 5 years and recurrence free survival probability in 5 years were also evaluated in relation to E-cadherin and $\beta$-caterin markers and are mentioned in Tables 5 and 6 , respectively. In this study, we found that lower global survival and lower survival free from recurrence were observed in situations of cervical dissemination and poor histological differentiation, and these were statistically significant. Establishing the median as the cut off point for the expression level, it was found that levels above this point for E-cadherin and $\beta$-catenin are associated with better recurrence free survival in 5 years, and for $\beta$-catenin with better disease free survival in 5 years.

Figure 3 refers to the global survival probability per $\beta$-catenin expression using the median as the cut off point. Significance was noticed between the survival curves.
Figures 4 and 5, respectively, represent the recurrence free survival probability per E-cadherin and $\beta$-catenin expression. The difference between the survival curves for both markers show statistical significance.

\section{DISCUSSION}

The marker expression for E-cadherin-catenin complex in laryngeal carcinomas has been studied by immunohistochemical analysis [16]. The presence of this complex is necessary for the maintenance of normal cell adhesion. On this basis, studies proposed that the reduction of this molecule increases the chance of invasion of the cell tissue adjacent to a carcinoma $[17,18]$. The reduction in expression of E-cadherin has been correlated with pathological characteristics of the tumor, such as tumor stage, degree of differentiation and lymph node involvement [2].

Studies published between 1996 and 2015 reveal an association between the reduction in E-cadherin expression and cervical metastasis in patients with larynx squamous cell carcinoma $[19,22]$. Comparatively, in this study, statistical significance was found in the presence of cervical metastasis in cases of low expression of E-cadherin. While evaluating $\beta$-catenin expression, Psyrri et al. [23], unlike this study, did not find statistical significance.

Among the studies that evaluated the correlation of the reduction of the above mentioned marker expression with the tumor site, only Ahmed et al. [22] and Goulioumios et al. [24] found significance when observing less expression of E-cadherin $(p=0.002)$ and $\beta$-catenin $(p=0.025)$, respectively, at the supraglottic site. In this present study, it was demonstrated that advanced supraglottic tumors present smaller quantitative expression of E-cadherin when compared to advanced glottic tumors $(p<0.001)$, unlike $\beta$-catenin expression, in which there is no such association.

In the evaluation of the tumor measure, revised studies were contradictory, and no statistical correlation with the expression of the markers analyzed was found. In this study, similarly to Psyrri et al. [23], not only in glottic, but also in supraglottic cases there was no significance between early and advanced tumors when it comes to variation of $\beta$-catenin expression. When the quantitative expression of E-cadherin was evaluated, it was observed that in the glottic site there is significance, with $p=0.004$. In supraglottic cases, it was noticed that the fall in expression in advanced tumors indicates some association; however, not significant $(p=0.051)$. Ahmed et al. [22] and Starska et al. [25] found association between the fall in E-cadherin expression and locally advanced tumors.

When the degree of histological differentiation was evaluated, there is statistically significant association, and 
Table 1: Distribution of cases according to demographic and clinical variables $(n=45)$

\begin{tabular}{|c|c|c|}
\hline Variable & Category/Measures & Freq. (\%)/Measures \\
\hline \multirow[t]{3}{*}{ Age (years) } & Variation & $47-79$ \\
\hline & Median & 62 \\
\hline & Average (standard deviation) & $63.0(8.2)$ \\
\hline \multirow[t]{2}{*}{ Gender } & Male & $33(73.3)$ \\
\hline & Female & $12(26.7)$ \\
\hline \multirow[t]{3}{*}{ Study groups } & Advanced glottic tumor & $15(33.3)$ \\
\hline & Advanced supraglottic tumor & $15(33.3)$ \\
\hline & Early glottic tumor & $15(33.3)$ \\
\hline \multirow[t]{2}{*}{ Tumor site } & Glottic & $30(66.6)$ \\
\hline & Supraglottic & $15(33.3)$ \\
\hline \multirow[t]{4}{*}{ T stage } & $\mathrm{T} 1$ & $12(26.6)$ \\
\hline & $\mathrm{T} 2$ & $5(11.1)$ \\
\hline & $\mathrm{T} 3$ & $16(35.6)$ \\
\hline & $\mathrm{T} 4$ & $12(26.6)$ \\
\hline \multirow[t]{2}{*}{ T stage } & $\mathrm{T} 1+\mathrm{T} 2$ & $17(37.8)$ \\
\hline & $\mathrm{T} 3+\mathrm{T} 4$ & $28(62.2)$ \\
\hline T stage + glottic site & $\begin{array}{l}\text { Glottic-(T1 + T2) } \\
\text { Glottic-(T3 + T4) }\end{array}$ & $\begin{array}{l}15(50.0) \\
15(50.0)\end{array}$ \\
\hline T- stage + supraglottic site & $\begin{array}{l}\text { Supraglottic-(T1 + T2) } \\
\text { Supraglottic-(T3 + T4) }\end{array}$ & $\begin{array}{c}2(13.3) \\
13(86.7)\end{array}$ \\
\hline \multirow[t]{2}{*}{$N$ stage } & No & $25(55.6)$ \\
\hline & $\mathrm{N}+$ & $20(44.4)$ \\
\hline Degree of histological & Well & $19(42.2)$ \\
\hline \multirow[t]{2}{*}{ differentiation } & Moderately & $11(24.4)$ \\
\hline & Poorly & $15(33.3)$ \\
\hline Follow-up time & Variation & $1-185$ \\
\hline \multirow[t]{2}{*}{ (months) } & Median & 62 \\
\hline & Average (standard deviation) & $54.5(40.1)$ \\
\hline \multirow[t]{2}{*}{ Death } & No & $25(55.6)$ \\
\hline & Yes & $20(44.4)$ \\
\hline Time for the occurrence of & $\begin{array}{c}\mathrm{N} \\
\text { Variation }\end{array}$ & $\begin{array}{c}20 \\
3-33\end{array}$ \\
\hline \multirow[t]{2}{*}{ loco-regional recurrence } & Median & 9.0 \\
\hline & Average (standard deviation) & $10.2(6.3)$ \\
\hline \multirow[t]{2}{*}{ Loco-regional recurrence } & No & $25(55.6)$ \\
\hline & Yes & $20(44.4)$ \\
\hline
\end{tabular}


Table 2: Distribution of cases according to the expression of E-cadherin and $\beta$-catenin $(n=45)$

\begin{tabular}{lcc}
\hline Variable & Category/Measures & Freq. \%/Measures \\
\hline E-cadherin & Variation & $7.9-100.0$ \\
& Median & 68.4 \\
& Average & 62.1 \\
& Standard deviation & 33.6 \\
E-cadherin expression Median cut off point & $\leq 68$ & $22(48.9)$ \\
B-catenin & $>68$ & $23(51.1)$ \\
& Variation & $0-100$ \\
B-catenin expression & Median & 51.0 \\
Median cut off point & Average & 44.3 \\
\hline
\end{tabular}

Table 3: Distribution of cases according to E-cadherin expression

\begin{tabular}{|c|c|c|c|c|c|c|c|}
\hline \multirow{2}{*}{ Variable } & \multirow{2}{*}{ Category } & \multicolumn{5}{|c|}{ E-cadherin (expression) } & \multirow{2}{*}{$p$-value } \\
\hline & & $N$ & variation & median & Average & SD & \\
\hline \multirow{2}{*}{ Age range (years) } & $\leq 62$ & 23 & $11.2-100.0$ & 81.5 & 66.2 & 33.8 & \multirow{2}{*}{0.339} \\
\hline & $>62$ & 22 & $7.9-100.0$ & 63.4 & 57.8 & 33.5 & \\
\hline \multirow[t]{2}{*}{ Gender } & Female & 12 & $15.3-100.0$ & 52.0 & 58.9 & 35.6 & \multirow[t]{2}{*}{0.979} \\
\hline & Male & 33 & $7.9-100.0$ & 72.1 & 63.3 & 33.3 & \\
\hline Tumor site & Glottic & 15 & $19.2-100.0$ & 68.4 & 66.2 & 21.6 & $<0.001$ \\
\hline$(\mathrm{T} 3+\mathrm{T} 4)$ & Supraglottic & 13 & $7.9-100.0$ & 19.1 & 25.8 & 24.5 & \\
\hline \multirow{2}{*}{ T stage + glottic site } & Glottic- (T1 + T2) & 15 & $20.0-100.0$ & 96.1 & 87.1 & 23.4 & \multirow{2}{*}{0.004} \\
\hline & Glottic-(T3 + T4) & 15 & $19.2-100.0$ & 68.4 & 66.2 & 21.6 & \\
\hline \multirow{2}{*}{ T stage + supraglottic site } & Supraglottic-(T1 + T2) & 2 & $63.0-100.0$ & 81.5 & 81.5 & 26.2 & \multirow{2}{*}{0.051} \\
\hline & Supraglottic-(T3 + T4) & 13 & $7.9-100.0$ & 19.1 & 25.8 & 24.5 & \\
\hline \multirow[t]{2}{*}{$N$ stage } & N0 & 25 & $19.2-100.0$ & 89.2 & 77.0 & 26.9 & \multirow[t]{2}{*}{0.001} \\
\hline & $\mathrm{N}+$ & 20 & 7.9-100.0 & 33.9 & 43.6 & 32.3 & \\
\hline Degree of & Well & 19 & $20.0-100.0$ & 96.1 & 87.8 & 21.2 & \multirow[t]{3}{*}{$<0.001^{*}$} \\
\hline histological & Moderately & 11 & $22.6-100.0$ & 63.0 & 57.5 & 26.9 & \\
\hline differentiation & Poorly & 15 & $7.9-88.6$ & 19.2 & 33.0 & 25.0 & \\
\hline
\end{tabular}

$p$-value obtained by the $U$ Mann-Whitney; ${ }^{*}$-value obtained by the Kruskal-Wallis test; SD = standard deviation.

by the Dunn's post hoc test, well differentiated tumors present E-cadherin measures higher than in moderately differentiated ( $p=0.007)$ and also higher than in the poorly differentiated tumors $(p<0.001)$. Moderately differentiated tumors present higher measures than those poorly differentiated $(p=0.031)$. In the quantitative expression of $\beta$-catenin, well differentiated tumors present higher expression than those poorly differentiated $(p=0.005)$, and in cases of moderately differentiated, they were bigger than the poorly differentiated tumors $(p=0.001)$, although there was no relationship with the well differentiated tumors $(p=0.184)$. The presented results were similar to those 
Table 4: Distribution of cases according to the $\beta$-catenin

\begin{tabular}{|c|c|c|c|c|c|c|c|}
\hline \multirow{2}{*}{ Variable } & \multirow{2}{*}{ Category } & \multicolumn{5}{|c|}{$\beta$-catenin (expression) } & \multirow{2}{*}{$p$-value } \\
\hline & & $N$ & variation & median & average & DP & \\
\hline \multirow{2}{*}{ Age range (years) } & $\leq 62$ & 23 & $0.0-100.0$ & 13.6 & 38.3 & 40.2 & \\
\hline & $>62$ & 22 & $0.0-100.0$ & 56.7 & 50.5 & 35.9 & 0.409 \\
\hline \multirow[t]{2}{*}{ Gender } & Female & 12 & $0.0-100.0$ & 51.8 & 47.9 & 32.8 & 0.698 \\
\hline & Male & 33 & $0.0-100.0$ & 51.0 & 43.0 & 40.4 & \\
\hline Tumor site & Glottic & 15 & $0.0-10.0$ & 67,6 & 48.7 & 43.2 & 0.199 \\
\hline$(\mathrm{T} 3+\mathrm{T} 4)$ & Supraglottic & 13 & $0.0-100.0$ & 11.7 & 29.0 & 34.1 & \\
\hline \multirow{2}{*}{$\begin{array}{l}\text { T stage }+ \text { glottic tumor } \\
\text { site }\end{array}$} & Glottic-(T1 + T2) & 15 & $0.0-100.0$ & 56.8 & 50.2 & 36.8 & \\
\hline & Glottic-(T3 + T4) & 15 & $0.0-100.0$ & 67.6 & 48.7 & 43.2 & 0.850 \\
\hline \multirow{2}{*}{$\begin{array}{l}\text { T stage }+ \text { supraglottic } \\
\text { tumor site }\end{array}$} & Supraglottic-(T1 + T2) & 2 & $50.4-81.8$ & 66.1 & 66.1 & 22.2 & \\
\hline & Supraglottic-(T3 + T4) & 13 & $0.0-100.0$ & 11.7 & 29.0 & 34.1 & 0.170 \\
\hline \multirow[t]{2}{*}{$N$ stage } & N0 & 25 & $0.0-100.0$ & 65.3 & 56.3 & 36.3 & 0.027 \\
\hline & $\mathrm{N}+$ & 20 & $0.0-100.0$ & 12.6 & 29.3 & 36.0 & \\
\hline Degree of & Well & 19 & $0.0-100.0$ & 60.0 & 53.1 & 37.5 & $0.004^{*}$ \\
\hline histological & Moderately & 11 & $0.0-100.0$ & 69.7 & 68.8 & 31.1 & \\
\hline differentiation & Poorly & 15 & $0.0-79.6$ & 6.9 & 15.1 & 24.6 & \\
\hline
\end{tabular}

$p$-value obtained by the Mann-Whitney test; ${ }^{p} p$-value obtained by the Kruskal-Wallis test; $\mathrm{SD}=\mathrm{standard}$ deviation.



Figure 1: Immunohistochemical staining for E-cadherin expression. (A) Early glottic squamous cell carcinoma (40×). (B) Advanced glottic squamous cell carcinoma with nodal disease $(40 \times)$. (C) poorly differentiated glottic squamous cell carcinoma $(40 \times)$. 
Table 5: Global survival probability in 5 years $(n=45)$

\begin{tabular}{|c|c|c|c|}
\hline Variable & $P$ & $\begin{array}{c}\text { Global survival } \\
\text { probability in } 5 \text { years }(\%)\end{array}$ & $p$-value \\
\hline Global survival & (45 patients) & 55.3 & \\
\hline Age range (years) & $\begin{array}{l}\leq 62 \\
>62\end{array}$ & $\begin{array}{l}60.9 \\
50.0\end{array}$ & 0.652 \\
\hline \multirow[t]{2}{*}{ Gender } & Female & 75.0 & 0.111 \\
\hline & Male & 48.2 & \\
\hline \multirow[t]{2}{*}{ Tumor site } & Glottic & 56.7 & 0.912 \\
\hline & Supraglottic & 53.3 & \\
\hline T stage + glottic site & $\begin{array}{l}\text { Glottic-(T1 + T2) } \\
\text { Glottic-(T3 + T4) }\end{array}$ & $\begin{array}{l}73.3 \\
40.0\end{array}$ & 0.049 \\
\hline T stage + supraglottic site & $\begin{array}{l}\text { Supraglottic (T1 + T2) } \\
\text { Supraglottic (T3 + T4) }\end{array}$ & $\begin{array}{l}50.0 \\
53.8\end{array}$ & 0.925 \\
\hline \multirow[t]{2}{*}{$N$ stage } & N0 & 68.0 & 0.041 \\
\hline & $\mathrm{N}+$ & 40.0 & \\
\hline Degree of & Well & 68.2 & 0.007 \\
\hline \multirow[t]{2}{*}{ histological differentiation } & Moderately & 72.7 & \\
\hline & Poorly & 26.7 & \\
\hline E-cadherin expression & $\begin{array}{l}\leq 68 \\
>68\end{array}$ & $\begin{array}{l}45.4 \\
64.8\end{array}$ & 0.169 \\
\hline$\beta$-catenin expression & $\begin{array}{l}\leq 50 \\
>50\end{array}$ & $\begin{array}{l}33.3 \\
74.7\end{array}$ & 0.002 \\
\hline
\end{tabular}

$p$-value obtained by the log-rank test.



Figure 2: Immunohistochemical staining for $\boldsymbol{\beta}$-catenin expression. (A) Well differentiated glottic squamous cell carcinoma $(40 \times)$. (B) Poorly differentiated glottic squamous cell carcinoma with nodal disease $(40 \times)$. 
Table 6: Recurrence free survival probability in 5 years

\begin{tabular}{|c|c|c|c|}
\hline Variable & Category & $\begin{array}{l}\text { Recurrence free survival probability in } \\
5 \text { years }(\%)\end{array}$ & $p$-value \\
\hline Global Survival & (45 patients) & 54.7 & \\
\hline Age range (years) & $\begin{array}{l}\leq 62 \\
>62\end{array}$ & $\begin{array}{l}56.2 \\
53.0\end{array}$ & 0.786 \\
\hline Gender & $\begin{array}{l}\text { Female } \\
\text { Male }\end{array}$ & $\begin{array}{l}58.3 \\
53.5\end{array}$ & 0.638 \\
\hline Tumor site & $\begin{array}{c}\text { Glottic } \\
\text { Supraglottic }\end{array}$ & $\begin{array}{l}69.3 \\
26.7\end{array}$ & 0.011 \\
\hline $\begin{array}{l}\mathrm{T}+\text { stage }+ \text { glottic tumor } \\
\text { site }\end{array}$ & $\begin{array}{l}\text { Glottic-(T1 + T2) } \\
\text { Glottic-(T3 + T4) }\end{array}$ & $\begin{array}{l}92.9 \\
46.7\end{array}$ & 0.006 \\
\hline T stage + supraglottic site & $\begin{array}{l}\text { Supraglottic (T1 + T2) } \\
\text { Supraglottic (T3 + T4) }\end{array}$ & $\begin{array}{l}50.0 \\
23.1\end{array}$ & 0.506 \\
\hline$N$ stage & $\begin{array}{l}\text { N0 } \\
\text { N+ }\end{array}$ & $\begin{array}{l}79.2 \\
25.0\end{array}$ & $<0.001$ \\
\hline $\begin{array}{l}\text { Degree of histological } \\
\text { differentiation }\end{array}$ & $\begin{array}{c}\text { Well } \\
\text { Moderately } \\
\text { Poorly }\end{array}$ & $\begin{array}{l}78.0 \\
72.7 \\
13.3\end{array}$ & $<0.001$ \\
\hline E-cadherin expression & $\begin{array}{l}\leq 68 \\
>68\end{array}$ & $\begin{array}{l}31.8 \\
77.5\end{array}$ & 0.002 \\
\hline$\beta$-catenin expression & $\begin{array}{l}\leq 50 \\
>50\end{array}$ & $\begin{array}{l}36.0 \\
70.8 \\
\end{array}$ & 0.005 \\
\hline
\end{tabular}

$p$-value obtained by the log-rank test.

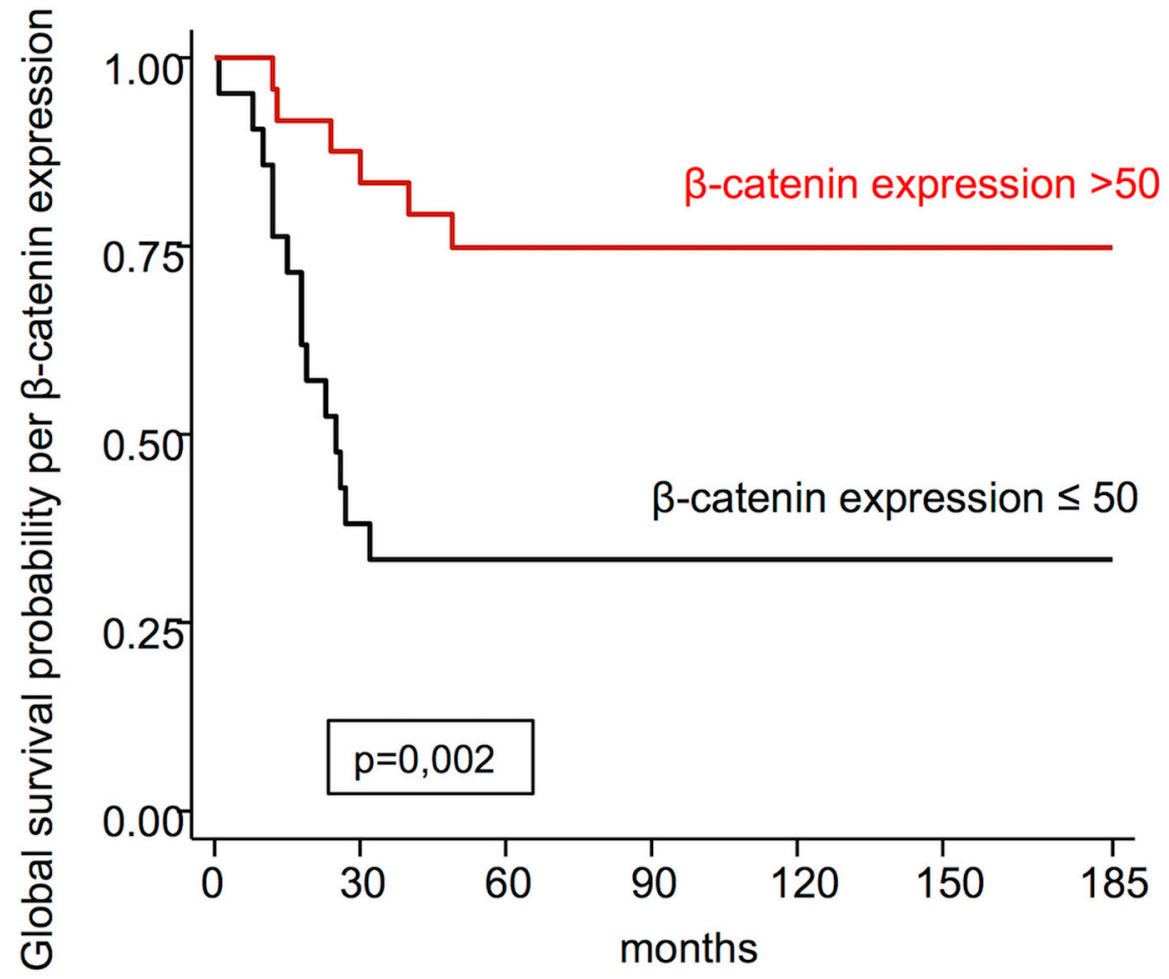

Figure 3: Global survival probability per $\beta$-catenin expression. 




Figure 4: Recurrence free survival probability per E-cadherin expression.

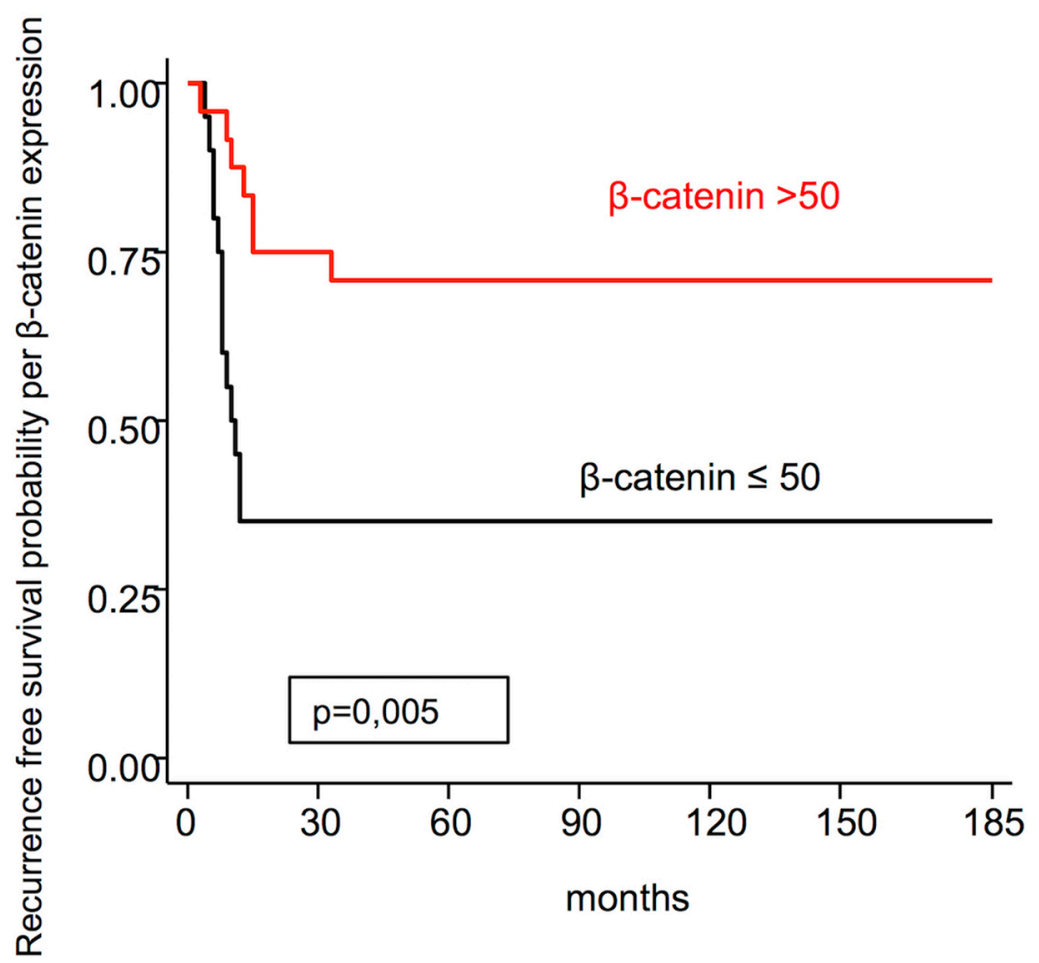

Figure 5: Recurrence free survival probability per $\beta$-catenin expression. 
found in the revised literature, in which there is low differentiation when the expression of markers E-cadherin $[19,21-23,26,27]$ and $\beta$-catenin [28] is smaller.

Few studies evaluated the relationship between $\beta$-catenin and larynx tumor behavior. Among them, Psyrri et al. [23] when assessing 289 patients with malignant laryngeal neoplasm did not find any statistical relationship with tumor progression, lymph node involvement and degree of histological differentiation. Only LopezGonzalez et al. [28], with 38 cases, found association between tumors of poorer differentiation with the fall of $\beta$-catenin expression.

When assessing global survival and disease free survival, it was found that advanced glottic tumors, the presence of cervical metastases and little differentiation present anegative influence in the prognosis, and the reduction of E-cadherin expression is related to all these events; a similar finding is reported by Li et al. [20] and Ahmed et al. [22].

The group in which there was absence of metastatic lymph nodes presented greater global survival $(68 \%)$ and disease free survival $(79.2 \%)$ in relation to cases with the presence of lymph node metastases (40 and $25 \%$, respectively), this association being of statistical significance ( $p=0.041$ and $p<0.001$, respectively) and similar to what was found in literature [29].

Greco et al. [29] found significant correlation between the increase in E-cadherin expression and the risk for worse global survival. This data was controversial, since the increase of E-cadherin expression would lead to the stabilization of the E-cadherin/ $\beta$ catenin complex. In the present study, we have not found significance in this association.

Using the median as the cut off point, we find that $\beta$-catenin expression $>50$ presents greater global survival $(74.7 \%)$ than $\beta$-catenin $\leq 50$ with survival in 5 years of $33.3 \%$ and this difference between the survival curves was statistically significant $(p=0.002)$; this relationship was only evaluated by the study of Greco et al. [29], who did not find significance.

Regarding disease free survival, the expression of E-cadherin $>68$, using the median as the cut off point, presented greater percentage for disease free survival $(77.5 \%)$ than $\leq 68(31.8 \%)$, and this difference was statistically significant $(p=0.002)$. Ahmed et al. [22], Capelleso et al. [30] and Li et al. [20] also found a positive relationship between disease free survival and high E-cadherin expression. $\beta$-catenin $>50$ presents greater disease free survival $(70.8 \%)$ than $\beta$-catenin $\leq 50$ $(36.0 \%)$ and this difference between the survival curves was statistically significant $(p=0.005)$, similar to Greco et al. [29].

Considering that the presence of cervical metastasis is an important factor for unfavorable prognosis, cases where there is low expression of the cited markers, which would lead to a greater risk of cervical metastasis, should be assessed regarding a more aggressive treatment and with short-term follow-up, especially those in which there was no indication for previous neck dissection. Another prognostic factor such as tumor progression was also verified where the low E-cadherin expression could represent locally advanced cases in the glottic site. Likewise, cases in which the markers expression is preserved, would tend to have a better differentiation and, therefore, better prognosis.

\section{CONCLUSIONS}

The reduction in expression of the E-cadherin and $\beta$-catenin markers in patients with malignant laryngeal neoplasm leads to a prognostic impact when related to the occurrence of cervical metastasis and greater local aggressiveness for E-cadherin in glottic tumors.

\section{CONFLICTS OF INTEREST}

The authors declare no conflicts of interest.

\section{REFERENCES}

1. Curado MP, Martins E. Incidência e mortalidade dos cânceres de cabeça e pescoço no Brasil. Rev Bras Cir CabeçaPescoço. 2006; 35:136-41.

2. Rodrigo JP, Domínguez F, Alvarez C, Manrique C, Herrero A, Suárez C. Expression of E-cadherin in squamous cell carcinomas of the supraglottic larynx with correlations to clinicopathological features. Eur J Cancer. 2002; 38:1059-64.

3. Hirohashi S. Inactivation of the E-cadherin-mediated cell adhesion system in human cancers. Am J Pathol. 1998; 153:333-39.

4. Snow GB, Annyas AA, van Slooten EA, Bartelink H, Hart AA. Prognostic factors of neck node metastasis. Clin Otolaryngol Allied Sci. 1982; 7:185-92.

5. Shah JP. Cervical lymph node metastases-diagnostic, therapeutic, and prognostic implications. Oncology (Williston Park). 1990; 4:61-69.

6. Takeichi M. Cadherin cell adhesion receptors as a morphogenetic regulator. Science. 1991; 251:1451-55.

7. Shimoyama Y, Hirohashi S, Hirano S, Noguchi M, Shimosato Y, Takeichi M, Abe O. Cadherin cell-adhesion molecules in human epithelial tissues and carcinomas. Cancer Res. 1989; 49:2128-33.

8. Ali S, Tiwari RM, Snow GB. False-positive and false-negative neck nodes. Head Neck Surg. 1985; 8:78-82.

9. Bowie GL, Caslin AW, Roland NJ, Field JK, Jones AS, Kinsella AR. Expression of the cell-cell adhesion molecule E-cadherin in squamous cell carcinoma of the head and neck. Clin Otolaryngol Allied Sci. 1993; 18:196-201.

10. Munck-Wikland E, Edström S, Jungmark E, Kuylenstierna R, Lindholm J, Auer G. Nuclear DNA content, 
proliferating-cell nuclear antigen (PCNA) and p53 immunostaining in predicting progression of laryngeal cancer in situ lesions. Int J Cancer. 1994; 56:95-99.

11. Tomasino RM, Daniele E, Bazan V, Morello V, Tralongo V, Nuara R, Nagar C, Salvato M, Ingria F, Restivo S, Dardanoni G, Vecchione A, Russo A. Prognostic significance of cell kinetics in laryngeal squamous cell carcinoma: clinicopathological associations. Cancer Res. 1995; 55:6103-08.

12. Shin DM, Voravud N, Ro JY, Lee JS, Hong WK, Hittelman WN. Sequential increases in proliferating cell nuclear antigen expression in head and neck tumorigenesis: a potential biomarker. J Natl Cancer Inst. 1993; 85:971-78.

13. Field GK. Oncogenes and tumor-suppressor oncogenes in squamous cell carcinoma of the head and neck. Oral Oncol Eur J Cancer. 1992; 28:67-76.

14. Birchmeier W. E-cadherin as a tumor (invasion) suppressor gene. BioEssays. 1995; 17:97-99.

15. Brierley JD, Gospodarowicz MK, Wittekind C. TNM Classification of Malignant Tumours. 8th ed. Oxford: Wiley Blackwell. 2017.

16. Rodrigo JP, Martínez P, Allonca E, Alonso-Durán L, Suárez C, Astudillo A, García-Pedrero JM. Immunohistochemical markers of distant metastasis in laryngeal and hypopharyngeal squamous cell carcinomas. Clin Exp Metastasis. 2014; 31:317-25.

17. Takes RP, Baatenburg de Jong RJ, Keuning J, Hermans J, Schuuring E, Van Krieken HJ. Protein expression of cancer associated genes: biopsy material compared to resection material in laryngeal cancer. Anticancer Res. 1998; 18:4787-91.

18. Schipper JH, Frixen UH, Behrens J, Unger A, Jahnke K, Birchmeier W. E-cadherin expression in squamous cell carcinomas of head and neck: inverse correlation with tumor dedifferentiation and lymph node metastasis. Cancer Res. 1991; 51:6328-37.

19. Franchi A, Gallo O, Boddi V, Santucci M. Prediction of occult neck metastases in laryngeal carcinoma: role of proliferating cell nuclear antigen, MIB-1, and E-cadherin immunohistochemical determination. Clin Cancer Res. 1996; 2:1801-08.

20. Li JJ, Zhang GH, Yang XM, Li SS, Liu X, Yang QT, Li Y, Ye J. Reduced E-cadherin expression is associated with lymph node metastases in laryngeal squamous cell carcinoma. Auris Nasus Larynx. 2012; 39:186-92.
21. Akdeniz O, Akduman D, Haksever M, Ozkarakas H, Müezzinoglu B. Relationships between clinical behavior of laryngeal squamous cell carcinomas and expression of VEGF, MMP-9 and E-cadherin. Asian Pac J Cancer Prev. 2013; 14:5301-10.

22. Ahmed RA, Shawky AA, Hamed RH. Prognostic significance of cyclin D1 and E-cadherin expression in laryngeal squamous cell carcinoma. Pathol Oncol Res. 2014; 20:625-33.

23. Psyrri A, Kotoula V, Fountzilas E, Alexopoulou Z, Bobos M, Televantou D, Karayannopoulou G, Krikelis D, Markou K, Karasmanis I, Angouridakis N, Kalogeras KT, Nikolaou A, Fountzilas G. Prognostic significance of the Wnt pathway in squamous cell laryngeal cancer. Oral Oncol. 2014; 50:298-305.

24. Goulioumis AK, Varakis J, Goumas P, Papadaki H. Differential $\beta$-catenin expression between glottic and supraglottic laryngeal carcinoma. Eur Arch Otorhinolaryngol. 2010; 267:1573-78.

25. Starska K, Forma E, Lewy-Trenda I, Papież P, Woś J, Bryś M. Diagnostic impact of promoter methylation and E-cadherin gene and protein expression levels in laryngeal carcinoma. Contemp Oncol (Pozn). 2013; 17:263-71.

26. Liu M, Lawson G, Delos M, Jamart J, Remacle M. Expression of E-cadherin adhesion molecule in vocal cord carcinomas. Eur Arch Otorhinolaryngol. 1997; 254:417-21.

27. Carico E, Radici M, Losito NS, Raffa S, Firrisi L, Fabiano A, Manola M, Vecchione A, Giovagnoli MR. Expression of E-cadherin and $\alpha$-catenin in T1 N0 laryngeal cancer. Anticancer Res. 2012; 32:5245-49.

28. Lopez-Gonzalez JS, Cristerna-Sanchez L, VazquezManriquez ME, Jimenez-Orci G, Aguilar-Cazares D. Localization and level of expression of $\beta$-catenin in human laryngeal squamous cell carcinoma. Otolaryngol Head Neck Surg. 2004; 130:89-93.

29. Greco A, De Virgilio A, Rizzo MI, Pandolfi F, Rosati D, de Vincentiis $M$. The prognostic role of E-cadherin and $\beta$-catenin overexpression in laryngeal squamous cell carcinoma. Laryngoscope. 2016; 126:E148-55.

30. Cappellesso R, Marioni G, Crescenzi M, Giacomelli L, Guzzardo V, Mussato A, Staffieri A, Martini A, Blandamura S, Fassina A. The prognostic role of the epithelial-mesenchymal transition markers E-cadherin and Slug in laryngeal squamous cell carcinoma. Histopathology. 2015; 67:491-500. 